"spontaneous combustion" which that genial novelist makes in his preface to the novel. We do not know what is M. Zola's authority for the possibility of such an occurrence, for he is not usually prone to exercise the licence accorded to writers of fiction (p. 205). A few pages further, and in marked contrast to that terrible event, there is detailed with painful minuteness the gentle ebbing away of life from epistaxis of the youthful and hrmophilic Charles seated at a table opposite to his great-great-grandmother, who is roused from the mental torpor of years by the scene before her eyes and with one lucid interval and return of memory succumbs to the shock she thereby receives. But to our thinking the most striking of all the situations in the book is the description of the death of Dr. Pascal from angina pectoris, which is too long to quote, but which shows how the man's will-power strove against the physical suffering and exhaustion of each successive attack, and how with the ruling passion strong in death the dying man nerves himself to supply in his genealogical tree the dare and mode of his own death, and to record the advent in the following year of the "Unknown Infant to be born in 1874 . What will it be?"'

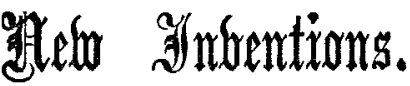

\section{CLAMP FOR OCCLUDING THE GOT IN INTESTINAL OPERATIONS.}

I HAVE devised a little clamp for occluding the gut in intestinal operations, and I have found it so simple and efficient that I think many will adopt it in preference to other instruments. It will be seen by the illustration that it consists of a metal rod, to one end of which a rubber ring is attached, whilst the other end is sharply conical, and connected with the opposite end of the rubber ring is a metal cap which fits the conical end of the rod. The sharp point of this rod is passed through the mesentery and behind the gut; the rubber ring is then drawn down over the front of the bowel

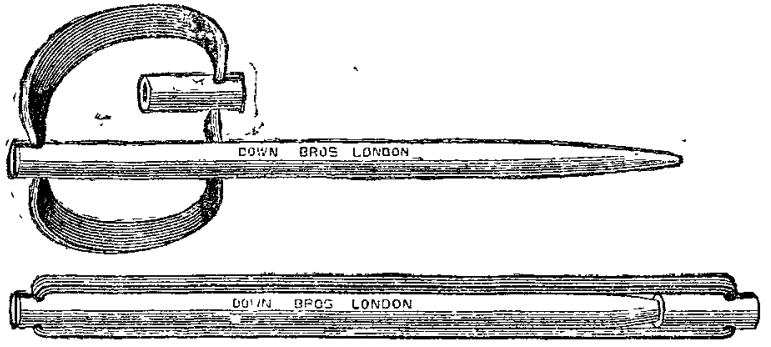

and the cap is fixed on to the conical end. By this means the bowel is absolutely occluded, being folded against the metal rod and compressed between it and the rubber band on either side. The coats of the bowel are absolutely unaffected by the very slight pressure which they sustain, and there is no risk of the clamp slipping or being displaced from its position. I have used this method in a clamp of my own construction for some time; the one shown is slightly modified to allow of easy removal of the rubber ring and thorongh cleansing. It has been made for me by Messrs. Down Bros., St. Thomas's-street, S. E.

St. Thomas's-street, S.E.

W. Arbuthnot Lane.

\section{IMPROVED BIFOCAL SPECTACLES.}

We have received from Mr. Head a paper which gives a description of a modification of the ordinary well-known Franklin or bifocal lens adapted for the use of those who are sufficiently long- or short-sighted to make the constant use of glasses almost a necessity. The paper appears to be a lecture giving a popular account of the formation of images on the retina in the normal eye and of the conditions present in hypermetropia and myopia. In the higher degrees of each defect a different glass is required for near and for distant rision, which in the Franklin lens is supplied by joining two lenses of different power in such a way that on looking up the patient looks through one glass, and on looking down through another. The objection to this arrangement is that the line of junction passes horizontally across the middle of the field of vision. As a matter of fact, a larger field is found to be advantageous for distant vision, and a smaller one for reading or for near objects generally. The difficulty has been partly surmounted by guiding the same glass with a segment of smaller area in its lower as compared with its upper part, which does away in great part with the sharply defined line of union of the two lenses. Mr. Head believes that he has made a still further improvement by cementing on the lower part of the glass a second supplementary disc or ellipse of glass, by means of which the desired power may be obtained. The reading lenses are thus reduced to a minimum of size and he claims for such glasses that they afford a greatly increased and much more complete field of vision for distant objects. The glasses can be obtained from $\mathrm{Mr}$. Baker of High Holborn.

\section{CHOLERA IN MANCHESTER.}

\section{To the Editors of THE LANCET.}

SIRs, - In consequence of the appearance in the local press of erroneous statements as to the prevalence of cholera and choleraic diarrhœa in Manchester I think that it is desirable to intimate that during the week before last there occurred here a few cases of severe bowel illness, which were attended by collapse and other alarming symptoms. In consequence of the presence of undoubted cholera at certain seaport towns in daily communication with Manchester every attack of choleraic diarrhoea, which has occurred here in an adult bas been treated as suspicious. The same careful investigations as to its origin and the same rigid precautions against its spreading have been practised that would have been resorted to had every attack been recognised from the first as one of Asiatic cholera. In these investigations I have had the advantage of the help of my colleague, Dr. Delépine, Professor of Pathology at Owens College, who has examined bacteriologically all the discharges, bowel contents \&c. in the cases which have been regarded as suspicious since the occurrence of the first known attack in Manchester. In three of the four cases bacteriologically examined (two of which are believed to be traceable to infection from Grimsby) the result of careful examination has been to show that the disease was cholera. Two of the patients have unfortunately died, and I am indebted to my friends Dr. Orchard, Dr. Paton and Dr. Sutherland for kindly undertaking the necessary necropsies on my behalf. The remaining patient, who is advanced in life, is apparently recovering, although she still remains extremely prostrate. The circumstances of a fourth suspicious case, which rapidly proved fatal, are under investigation, and the result will, I trust, be definitely known in the course of another day or two. From the evidence, however, which Dr. Delépine has obtained up to the present time he inclines to the belief that the disease in this instance was not true cholera.

It is much to be regretted that the Manchester public suffer themselves to be misled by the circulation of unauthorised and sensational reports respecting the local prevalence of cholera. In the improbable event of cholera becoming seriously epidemic amongst us the public will be kept duly informed by means of the ordinary weekly health returns, which are widely circulated in the city, and reliable information on the subject can always be obtained at the Public Health Office. At present there is nothing of the nature of an epidemic of cholera or of choleraic diarrhoea in Manchester and no fresh case of a suspicious character, has been reported since the beginning of last week. The few cases hitherto reported have been sporadic in character, and every known precaution has been taken to prevent the spread of infection from the persons attacked. During the last four weeks the deaths from infantile diarrhoa have grown steadily fewer week by week, the deaths from that disease last week having fallen to only one-third of the average weekly number registered during part of the month of July last.

I am, Sirs, your obedient servant, JoHN TATHAM.

Public Health Office, Town Hall, Manchester, Sept. 25th, 1893. o 3 